\title{
PERFORMANS DEĞERLENDİRMESİNE ÇOK ÖLÇÜTLÜ BÜTÜNLEŞİK BİR YAKLAŞIM
}

\author{
Mehmet YÜKSEL \\ Alparslan Anadolu Lisesi, Yenimahalle, Ankara \\ m06yuksel@hotmail.com
}

(Geliş/Received: 23.12.2014; Kabul/Accepted: 05.08.2015)

ÖZET

Eğitim sisteminin performansının belirlenmesi eğitim yöneticileri, karar vericiler ve planlamacılar açısından bilinmesi gereken önemli bir bilgidir. Bu çalışmada, eğitim faaliyetinin doğasının çok faktörlü bir yapıya sahip olduğu düşüncesinden hareketle, bir eğitim sisteminin performansını değerlendirmeye yönelik bir algoritma önerilmiştir. Çalışmada önerilen algoritmanın uygulaması bir üniversitenin lisans düzeyinde eğitim veren bir bölümüne yönelik yapılmıştır. Çalışmada eğitim sistemi; yönetim, altyapı, öğretimin etkililiği, öğrenciler, endüstri ve toplumla etkileşim, müfredat dışı etkinlikler ve araştırma geliştirme faktörlerinden oluşmuştur. Çalışmada faktörler arasındaki ilişki DEMATEL (The Decision Making Trial and Evaluation Laboratory) tekniğiyle ve faktörlerin ağırlıkları ise ANP (Analitik A ğ Prosesi) tekniğiyle belirlenmiştir. Bütüncül yaklaşımı temel alan bu çalışmanın sonuçlarına göre bir eğitim sisteminin performansının ne düzeyde gerçekleştiği belirlenebilmiştir. Çalışmada önerilen algoritmayla her bir eğitimsel faktörün performans düzeyi belirlenebilmiştir. Bununla birlikte faktörlere göre performans sapma düzeyi ve eğitim sisteminin genel performans sapma düzeyi önerilen yaklaşımla hesaplanabilinmiştir.

Anahtar Kelimeler: Performans değerlendirme, çok ölçütlü karar verme, eğitim sistemi

\section{AN INTEGRATED APPROACH FOR EVALUATING PERFORMANCE BY MULTI-CRITERIA}

\begin{abstract}
Determining the education system's performance is important information that should be aware of by the education directors, decision makers and the planners. In this research, from the idea that claims the nature of the education activity has a multi-criteria structure; an algorithm to evaluate the performance of an education system is proposed. The application of the proposed algorithm in the research is studied in one of the departments which provide education of undergraduate academic degree in a university. In the research, the education system constitutes of the factors those are management, substructure, efficiency of the teaching, students, interaction between the industry and the society, extracurricular activities and research development. In the research, the relationship among the factors is determined by The Decision Making Trial and Evaluation Laboratory (DEMATEL) technique and the weights of the factors are determined by Analytic Network Process (ANP) technique. As a result of this study which is based on the integrated approach; it is determined in what degree the education system's performance accrued. Performance level of each education factor is also determined by the proposed algorithm in the research. Besides, the deviation level of performance according to the factors and the deviation level of general performance of the education system could be calculated by the proposed approach.
\end{abstract}

Keywords: Performance evaluation, multi-attribute decision making techniques, education system

\section{GIRIŞ (INTRODUCTION)}

Eğitim, doğası gereği çok sayıda değişkene bağlı ve bir süreç içerisinde gerçekleşebilen bir faaliyettir.
Dolayısıyla herhangi bir eğitim seviyesinde verilen bir eğitim faaliyetinin amacına ulaşması, karmaşık örüntüsü olan bir yapı ve işleyişin sonucunda mümkün bulunmaktadır. Bu tür çoklu değişkenlerden 
oluşan yapıların bütüncül yapı ve işleyişleri, onu oluşturan unsurların niteliklerinden farklı olabilmektedir. Eğitim faaliyetinin niteliğinin de çoklu değişkenlerden oluşan sistem kavramı bağlamında düşünülen $[1,2]$ bir olgu olduğu görülmektedir. $\mathrm{Bu}$ tür yaklaşım, bir eğitim kurumunun işleyişi ve sonuçlarının değerlendirilmesi, bir diğer ifadeyle amaçların gerçekleşme derecesini ifade eden performans değerlendirmesi açısından önemlidir. Sistem yaklaşımı bağlamında bir eğitim sisteminin performansı düşünüldüğünde, eğitim sistemini oluşturan unsurların performans üzerinde doğrudan etkileri bulunduğu gibi, unsurların biri biriyle olan etkileşimi [1] de performansı etkileyebilir. Bir eğitim sisteminin, örneğin bir eğitim kurumunun ya da biriminin amacına ulaşması, eğitim sistemini oluşturan unsurların tek başına fonksiyonu olarak düşünmek genellikle mümkün değildir. Eğitim sisteminin amacını gerçekleştirmesi ya da eğitim kurumunun belirlenmiş olan amaca ulaşma düzeyi, aynı zamanda eğitim sisteminin bir unsurunun diğer bir unsur ile olan ilişkisi ya da etkileşiminin sonucu da olabilmektedir. Örneğin bir eğitim sisteminde öğretimin etkililiğinin performansı belirlemedeki rolü; altyapı, donanım, laboratuvar gibi unsurlara bağlı ya da bu unsurlarla ilişki ve etkileşim düzeyine göre farklılık gösterebilir. Bu yapı ve ilişkiler, bir eğitim sisteminin performansının değerlendirilmesinde, sistemi oluşturan bütün unsurların biri biriyle olan etkileşimlerini dikkate alan bir örüntüyle ölçülmesi ve değerlendirilmesinin önemini göstermektedir.

Eğitim sisteminin performansının belirlenmesinde karşılaşılan başka bir konu, diğer sistemlerde olduğu [3] gibi, eğitim sisteminde de her bir unsurun sistem içerisindeki etkisinin farklı düzeylerde gerçekleşebilmesidir. Eğitim sisteminin amacına ulaşmasında onu oluşturan ana ve alt unsurların rollerinin göreli ağırlıkları farklılık gösterebilecektir. $\mathrm{Bu}$ nedenle bir eğitim sisteminin performansının değerlendirilmesinde bu farklılıkları dikkate alabilen bir yaklaşım gerekmektedir. Eğitim sistemi performansının belirlenmesinde dikkate alınması gereken konulardan bir diğeri ise, sistemin bir bütün olarak değerlendirilebilmesidir. $\mathrm{Bu}$ gereklilik yukarıda ifade edilen eğitim faaliyetinin sistem yaklaşımı çerçevesinde düşünülmesinden kaynaklanmaktadır. Sistem olgusu bakış açısında bir eğitim sisteminin performansını yalnızca bir gösterge ile ifade edebilmek olası değildir.

Taylor [4] tarafindan ilk kez bilimsel çalışmalara konu edilen performans kavramının bugüne kadar çok sayıda araştırmalara konu edildiği görülmektedir. Bilimsel Yönetim Yaklaşımı [4] ile gözlem ve araştırma konusu edilen performans kavramının ölçülmesi ve değerlendirilmesine yönelik düşünce biçimi ve yönteminin süreç içerisinde farklılaştığı görülmektedir. Son dönemde, performans kavramının geleneksel yaklaşımın tersine bütüncül bir bakış açısıyla açıklanmaya ve modellenmeye çalışıldığı görülmektedir $[5,6]$. Bu tür çalışmaların aslında Kaplan ve Norton'un [7] kavramsal ve uygulama boyutlarıyla literatüre kazandırmış oldukları Balanced Scorecard (BSC) yaklaşımından kaynaklandığı ya da esinlendiği de söylenebilir. Balanced Scorecard yaklaşımı bir şirketin ya da bir sistemin performansının sinırlı sayıda boyut ya da gösterge ile tanımlanmasını yeterli olmadığını ileri sürmektedir. Kaplan ve Norton [8,9] bu düşünceden hareketle, bir şirket için önermiş oldukları performans değerlendirme modelinde finansal durum, müşteriler, içsel süreçler, öğrenme ve gelişme boyutlarının dengede olmasını ileri sürmüşlerdir. Böylece BSC yaklaşımı bir şirketin performansının ölçülmesinde, yalnızca finansal göstergelerle değil buna ilaveten müşteri, içsel süreçler, öğrenme ve gelişme boyutlarının da dikkate alınması gerektiğini savunmuşlardır [10]. Bir işletme ya da bir sistemin performansının değerlendirilmesinde bütüncül bir karakteristik öneren BSC modeline yönelik bazı eleştiriler yapılmıştır $[10,11,12,13,14$,$] . Eleştirel$ bağlamda yapılan çalışmalarda, nitelikleri farklı olan BSC boyut ve göstergelerin konsolidasyon sorunu $[10,11,12]$ ve bu farklı boyutların içerdiği performans göstergelerinin göreli ağırlıklarının belirlenmesi sorununun çok ölçütlü değerlendirme yöntemleri ile çözümlenmeye çalışıldığ görülmüştür $[10,12,13,15]$. Herhangi bir eğitim kurumu ya da bir eğitim sistemi açısından bakıldığında, esasında sorunun benzer olduğu görülmektedir. Eğitim sisteminin de performansının yalnızca bir boyut ya da sınırlı sayıda gösterge ile belirlenemeyecek kadar yalın bir yapısının olduğunu söylemek olası değildir. Gerçek yaşamda karşılaşılan diğer olgu ve olayların konu edildiği problemlerde $[5,16]$ karşılaşıldığı gibi, eğitim sisteminin de doğası gereği dinamik yapısı ve karmaşık $[17,18]$ bir örüntüsü bulunmaktadır. Bu nedenle bir eğitim sisteminin performansının değerlendirilmesine yönelik ölçme ve değerlendirme yaklaşımının çok boyutlu özelliği taşıyan nitelikte olması gerekmektedir.

Literatür incelemesinde insan kaynakları alanında ya da çeşitli sistemlerin performansının [5,10,19,20,21] değerlendirmesinde çok ölçütlü karar verme (ÇÖKV) yaklaşımlarını kullanan çalışmalar bulunmaktadır. Literatürde yer alan çok ölçütlü karar verme yaklaşımlarını kullanan çalışmalarda dikkat çeken unsurun performans değerlendirme modellerinin içerdiği faktörlerin ilişkili olarak Analitik Ağ Prosesi (ANP) $[10,13,16]$ ve ilişkisizlik bağlamında Analitik Hiyerarşi Prosesi (AHP) [5,6,12,15,22] ile ağırlıklandırmaların hesaplandığı görülmüştür. Öte yandan performans değerlendirme çalışmalarında önerilen modellerde faktörler arasındaki ilişkiyi ANP yaklaşımıyla dikkate alan çalışmalarda [23] örüntünün sezgisel olarak belirlendiği görülmektedir. Böylesi bir yaklaşım neticesinde belirlenmiş olan ilişkiler örüntüsünün, inceleme konusu edilen sistemi 
oluşturan yapının içerdiği faktörlerin biri biriyle olan ilişki örüntüsünün gerçek durumundan farklı olabilir. $\mathrm{Bu}$ nedenle bir sistemin performans değerlendirme modelindeki faktörler arasında ilişki ve etkileşimin değerlendirilmek istenen sistemin doğasını yansıtan bir nitelikte olması gerekmektedir. Literatürde farklı problemlerde faktörler arasındaki olası ilişkileri analitik ve matrisyel yaklaşımla belirlemeye yönelik $[19,20,21,24]$ çalışmalar da yapılmıştır. Bu tür çalışmaların sonuçlarının değerlendirmesine göre faktörler arasındaki ilişkinin çok ölçütlü bir yaklaşım içeren DEMATEL (The Decision Making Trial and Evaluation Laboratory) tekniğiyle belirlenebileceği görülmüştür.

Literatürde eğitim birimi ya da kurumlarını kapsayan performans değerlendirmesi çalışmalarında da [18,22] çok ölçütlü yaklaşımlar kullanılmıştır. Öte yandan literatürde eğitim kurumları performansını BSC konseptinde çok ölçütlü yaklaşımlarla inceleyen $[14,25]$ çalışmalar da yapılmış olmakla birlikte, bunların yeterince bir eğitim sistemini temsil edebilir yapıda olduğunu söylemek olanaklı değil. Bunun başlıca nedeni BSC'nin önermiş olduğu boyutlar kapsamında bir eğitim kurum ya da biriminin performans değerlendirmesinin eğitim kurum ya da biriminin yapısını oluşturan faktörlerin işleyişini temsil edememesi ya da gösterge niteliği taşıyamaması sorunudur. Bir diğer ifadeyle eğitim sisteminin kendine özgü bir karakteristiğinin olması BSC çerçevesinde değerlendirilmesinde güçlük ve temsil sorunu oluşturmaktadır. Bir eğitim sisteminin performansını, iktisadi amaçları önemli ve ağırlıklı olan bir sistem gibi düşünülmesi ya da benzer boyutlarla performansının değerlendirilmesinin sorunlu olduğu söylenebilir. Çünkü bir eğitim sisteminin performansını BSC yaklaşımının önermiş olduğu boyut ve göstergelerle temsil etmeye çalışmak, eğitim sisteminin özellikleri ve yapısı açısından kabul edilebilir olduğu söylenemez. Literatürde bir eğitim sistemine ilişkin performansı, eğitim olgusunun faktörleriyle çok ölçütlü yaklaşımlarla araştırma konusu edinen [18] çalışmalarda ise bir sıralama ya da ağırlıklandırmanın yapıldığı görülmektedir. Oysaki eğitim sistemine ilişkin bütüncül performansın ne düzeyde olduğunun bilinmesi sistemin işleyişi açısından önemlidir. Bununla birlikte, bir eğitim sistemini oluşturan faktörlerin performans düzeyinin ayrıntılı olarak görülebilmesi, karar vericilerin eylem ve davranışlarının yönünü belirlemesi bakımından önemli olan bir diğer konudur. Bir sistemin işleyişine yönelik değerlendirmeler için gerekli olan bu yaklaşım biçimi esasında literatürde bütüncül çerçevede problemleri konu edinen $[10,26,27]$ çalışmalar bulunmakla birlikte bir eğitim sisteminin performansının belirlenmesi ilk kez çalışma konusu edilmiştir.

$\mathrm{Bu}$ çalışmanın başlıca amacı yukarıda ifade edilen bilgiler bağlamında, bir eğitim sisteminin performansını ölçmeye ve değerlendirmeye yönelik çok ölçütlü bir yaklaşım önermektir. Çalışmada önerilen algoritmayla bir eğitim sisteminin performansının ölçülmesi ve değerlendirilmesinde yukarıda belirtilen eksiklikleri dikkate alan bir değerlendirme yapılabilmektedir.

Bu çalışmanın diğer bölümlerinin başlık ve içerikleri şöyle biçimlendirilmiştir: İkinci bölümde çalışmanın yöntemi verilmiştir. Yöntem bölümünde çalışmada önerilen performans değerlendirme modelinin algoritması ve algoritmanın çözümünde kullanılan teknikler açıklanmıştır. Çalışmanın üçüncü kısmında önerilen modele ilişkin uygulama yer almıştır. Dördüncü bölümde ise önerilen modelin uygulamasına yönelik tartışma ve sonuçlar verilmiştir.

\section{YÖNTEM (METHOD)}

$\mathrm{Bu}$ çalışmanın giriş kısmında ifade edilen eğitim sisteminin performansının değerlendirilmesi probleminin çözümüne yönelik önerilen algoritmanın başlıca adımları şöyledir:

Adım 1: Eğitim sisteminin performansının değerlendirmesini yapacak uzman ekibin oluşturulması.

Adım 2: Eğitim sistemini oluşturan faktör ve altfaktörlerin belirlenmesi.

Adım 3: Başlangıç modelinin oluşturulması.

Adım 4: Eğitim sistemi faktörleri arasındaki ilişkinin DEMATEL tekniğiyle belirlenmesi.

Adım 5: Eğitim sistemi performans değerlendirme modelinin oluşturulması.

Adım 6: Eğitim sistemi faktörlerinin ilişkisizlik göreli ağırlıklarının belirlenmesi.

Adım 7: Eğitim sistemi faktörlerinin iç bağımlılık matrisinin oluşturulması.

Adım 8: Eğitim sistemi faktörlerinin iç bağımlılık ağırlıklarının hesaplanması.

Adım 9: Eğitim sistemi alt faktörlerinin göreli ağırlıklarının hesaplanması.

Adım 10: Eğitim sistemini oluşturan faktörlerin genel ağırlıkların belirlenmesi.

Adım 11: Eğitim sistemi performans düzeyinin belirlenmesi.

Bir eğitim sisteminin performansını ölçmeye ve değerlendirmeye yönelik çok ölçütlü bir yaklaşıma ilişkin uygulama adımlarını gösteren akış şeması Şekil 1'de verilmiştir. Yukarıda adımları verilen algoritmanın çözümünde DEMATEL ve ANP teknikleri kullanılmıştır. $\mathrm{Bu}$ tekniklerin kullanılmasının başlıca nedeni, çalışmada önerilen eğitim sistemi performans değerlendirme algoritmasının bütünleşik bir ölçme ve değerlendirme yaklaşımı gereksinimi göstermesidir. 


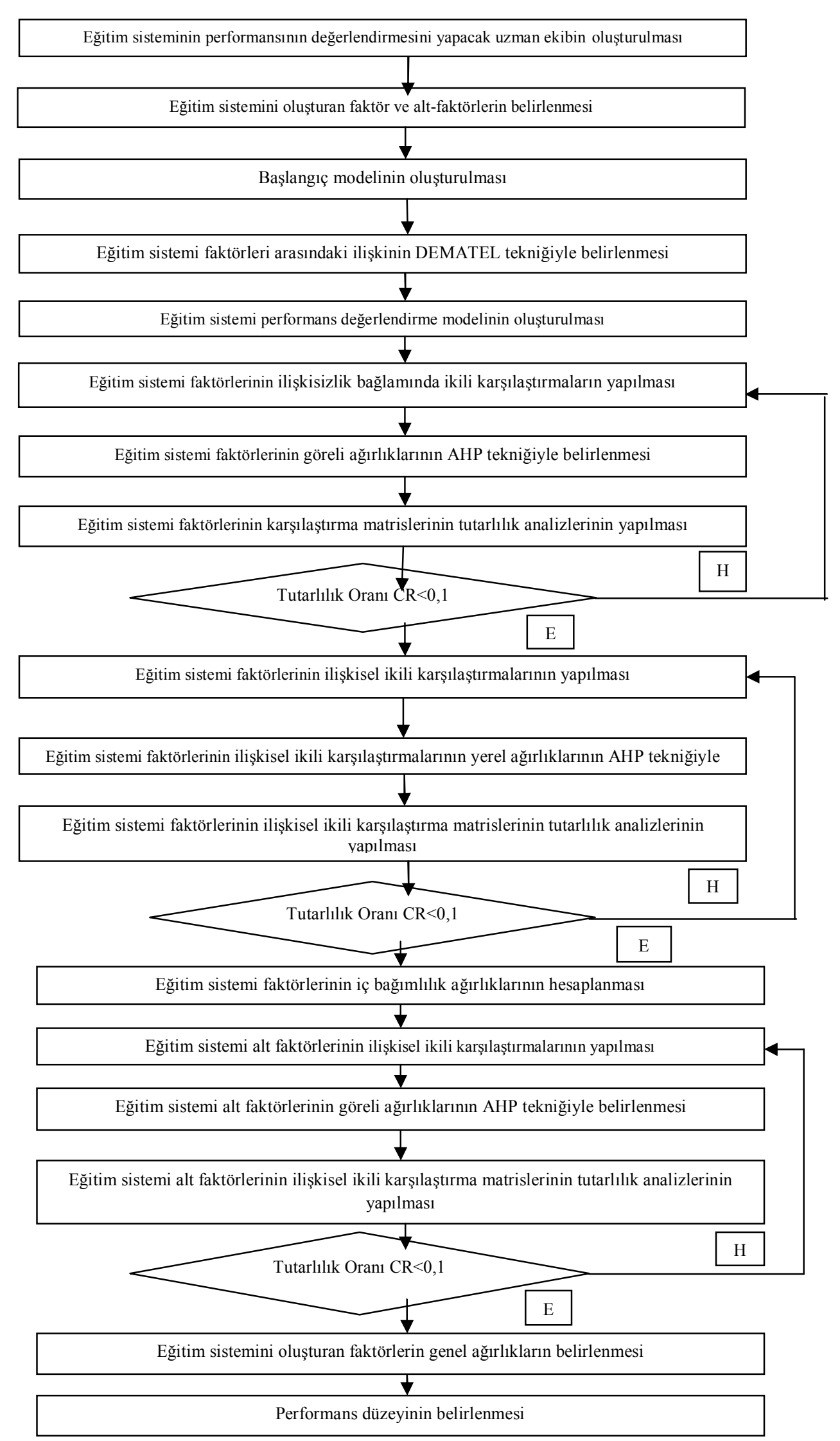

Şekil 1. Performans değerlendirme akış şeması (Performance assesment flow chart) 
DEMATEL tekniği çalışmada faktörler arasındaki ilişki ve etkileşimin belirlenmesinde kullanılmıştır. Graf teori temelli DEMATEL tekniği bir olgu ya da olayın içerdiği faktörleri graf teori temelli açıklayan bir tekniktir. Faktörler arasındaki nedensel ilişki örüntüsünü belirlemeye olanak veren bir yaklaşımdır. DEMATEL tekniği araştırma konusu edilen sistemin bileşenleri arasındaki yapı ve ilişikleri belirleyebilmektedir. DEMATEL bu yönüyle karmaşık ya da iç içe geçişken problemlerin örüntüsünün anlaşılmasına olanak vermektedir. $\mathrm{Bu}$ üstünlügünden dolayı DEMATEL tekniği literatürde çok sayıda çalışmaya $[18,28,29,30,31,32]$ konu edilen bir yaklaşım olmuştur.

Çalıșmada kullanılan diğer çok ölçütlü teknik ANP ise Saaty [33] tarafından AHP'nin temelleri üzerinde geliştirmiş olduğu bir yaklaşımdır. ANP, faktörlerin ağırlıklarının belirlenmesinde faktörler arasındaki ilişkileri ve etkileşimleri dikkate alabilmektedir. Bu yönüyle faktörler arasındaki ilişkinin ve etkileşimin önemli olduğu çok ölçütlü problemlerin çözümünde üstünlük sağlamaktadır [28]. DEMATEL [18,28,29,30,32], AHP [33,34,35] ve ANP'nin [36,37] kuramsal temelleri ve uygulama boyutunu konu edinen çok sayıda çalışma literatürde yer almaktadır. Literatürde yer alan çalışmaların ulaştığı kapsam ve düzey bu ÇÖKV yaklaşımların yaygınlıkla kullanıldığını göstermektedir. $\mathrm{Bu}$ nedenle bu tekniklerin algoritmaları ve matematiksel işlemlerinin bu çalışmada tekrar verilme ihtiyacı görülmemiştir.

\section{UYGULAMA (APPLICATION)}

Adım 1: Eğitim sisteminin performansının değerlendirmesini yapacak uzman ekibin oluşturulması. Algoritmanın birinci adımında çalışmanın gereksinim duyduğu verileri ve eğitim sistemine ilişkin performans değerlendirme faktörlerini belirleyecek uzman ekip oluşturulmuștur. Çalışmada önerilen performans değerlendirme algoritmasının uygulaması bir üniversitenin lisans düzeyinde eğitim veren programına yönelik yapılmıştır. $\mathrm{Bu}$ nedenle gereksinim duyulan veriler ilgili programın bölüm başkanı, bölüm başkan yardımcısı ve çalışmanın yazarından oluşan bir ekibin değerlendirmesinden sağlanmıştır.

Adım 2: Eğitim sistemini oluşturan faktör ve altfaktörlerin belirlenmesi. Çalışmanın ikinci adımında bu çalışmanın kapsamında analiz birimi olarak belirlenen lisans eğitimi veren bölümün performans değerlendirilmesinde temel alınan faktör ve alt faktörler belirlenmiştir. Bölümün eğitim ve öğretim alanı, yapısı ve işleyişi dikkate alınarak, ilgili literatür incelemesi neticesinde performans değerlendirme faktörleri belirlenmiştir [22,38,39,40]. Belirlenen faktörler uzman ekibin görüşüne sunulmuş ve onaylama sonrasında çalışmada değerlendirmeye esas alınmıştır. Buna göre bu çalışmada performans değerlendirilmesinde temel alınan faktör ve alt faktörler şöyledir:
- Yönetim(YO)

- Amaçların belirlenmesi (YO1)

- Eğitim politika ve programların oluşturulması (YO2)

- Eğitim ve öğretim etkililiğinin kontrolü (YO3)

- $\quad$ Öğrencilerin yönetime ulaşabilmesi (YO4)

- Öğrenci danışmanlık faaliyetleri (YO5)

- Öğrenci problemlerini çözmek (YO6)

- Altyapı (AY)

- $\quad$ İyi donanımlı derslikler (AY1)

- İyi donanımli laboratuarlar (AY2)

- Okuma odalar1 (AY3)

- Internet erişimi (AY4)

- $\quad$ Kütüphane (AY5)

- Barınma ve beslenme hizmeti (AY6)

- Öğretimin etkililiği (OE)

- $\quad$ Müfredatın yapısı (OE1)

- $\quad$ Öğretim elemanlarının öğretim becerisi (OE2)

- Öğretim elemanlarının akademik niteliği (OE3)

- Kalite geliştirme programlarının etkinliği (OE4)

- Öğretim elemanları için uygun akademik atmosfer (OE5)

- Haftalık ders programının uygunluğu (OE6)

- Öğrenciler (OR)

- $\quad$ Lisans yerleştirme sınavı yüzdelik düzeyi (OR1)

- $\quad$ Öğrencinin öğrenme performansı (OR2)

- Öğrencinin öğretim elemanını değerlendirebilmesi (OR3)

- $\quad$ Öğrenci değişim programları (OR4)

- Endüstri ve toplumla etkileşim (ET)

- $\quad$ Sosyal sorumluluk projeleri (ET1)

- Sanayi işbirliği çalışmaları (ET2)

- Danışmanlık faaliyetleri (ET3)

- Toplumda farkındalık oluşturma (ET4)

- Müfredat dışı etkinlikler (MU)

- $\quad$ Alan dişı bilimsel etkinlikler (MU1)

- Kültürel etkinlikler (Güzel sanatlar, Edebi çalışmalar) (MU2)

- $\quad$ Sportif faaliyetler (MU3)

- Yabancı dil çalışmaları (MU4)

- $\quad$ Kariyer etkinlikleri (MU5)

- $\quad$ Araştırma ve geliştirme (AG)

- Bölüm öğretim elemanlarının SSCI ve SCI indeksli dergilerde yayımlanmış makale sayısı (AG1)

- Bölüm ve öğretim elemanlarının yürüttüğü ulusal ve uluslararas1 projeler (AG2) 
- Bölüm ve öğretim elemanlarının aldığı patentler (AG3)

- Bölüm öğretim elemanlarının Web of Science atıf sayısı (AG4)

- Bölüm öğretim elemanlarının Web of Science hindeks düzeyi (AG5)

- Bölümün İndeksli dergi yayını (AG6)

Adım 3: Başlangıç Modelinin Oluşturulması. Bu aşamada eğitim sistemini oluşturan faktör ve alt faktörler dikkate alınarak performans değerlendirme başlangıç modeli oluşturulmuştur. Başlangıç modelini oluşturmanın temel gerekçesi, eğitim sistemini oluşturan faktörlerin gruplandırılması ve bunların biri biriyle ilişkisinin olup olmadığının belirlenmesidir. Ancak başlangıç modelinin yapısı ve örüntüsüne ilişkin geçerlik sorunu dördüncü adımda DEMATEL tekniğiyle analiz konusu edilmiştir. Faktörler arasında başlangiçta düşünülen ilişkiler uzman ekibin görüşüne göre belirlenmiştir. Buna göre çalışmanın başlangıcında oluşturulan eğitim sistemi performans değerlendirme modeli ve faktörler arasında varsayılan ilişki ağı şekil 2'de verilmiştir.

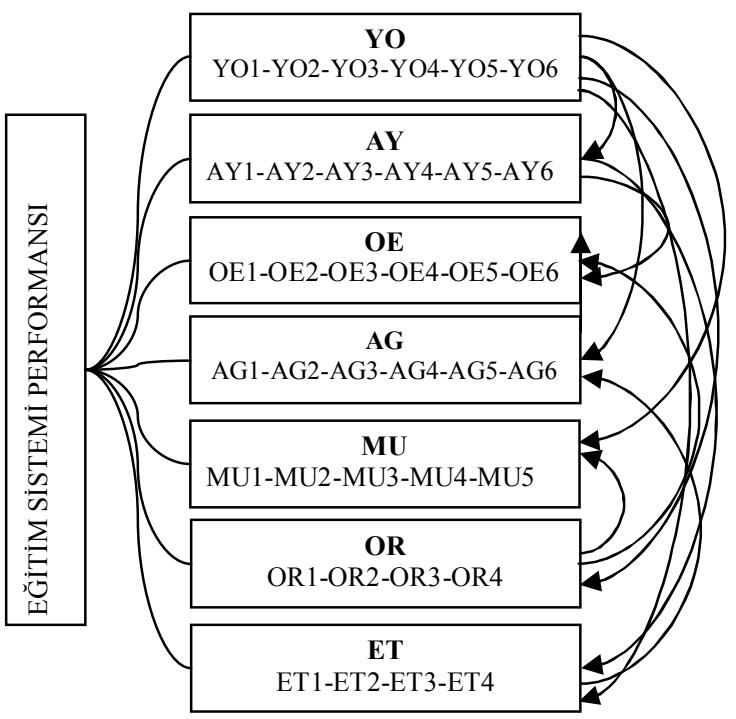

Şekil 2. Performans değerlendirme başlangıç modeli (Initial model for performance assesment)

Adım 4: Eğitim sistemi ana faktörleri arasındaki ilişkinin DEMATEL tekniğiyle belirlenmesi. Çalışmanın üçüncü adımında yargısal bir yaklaşımla faktörler arasında belirlenmiş olan ilişkilerin geçerliği bu adımda DEMATEL tekniğiyle analiz edilmiştir. DEMATEL tekniğinin ilişkilerin belirlenmesinde kullanılmasının başlıca amacı faktörler arasındaki ilişkileri temsil edebilen örüntüyü ve dolayısıyla performans değerlendirme modelinin geçerlik sorunu içermeyen ilişki ağını oluşturmaktır.

DEMATEL tekniğiyle faktörler arasındaki ilişkiyi belirlemek için başlangıç direkt ilişki matrisi uzman ekibin görüşüne göre oluşturulmuştur. Karar vericilerin görüşleri faktörlerin biri biriyle olan ikili karşılaştırmaları neticesinde düşünülen ilişki ve etkileşime göre; etkisiz (0), düşük etki (1), orta etki (2), yüksek etki (3) ve çok yüksek etki (4) şeklinde beş düzeyde sınıflandırılmıştır. Buna göre uzman ekibin ortak görüş birliği neticesinde yapmış oldukları değerlendirmelere göre oluşturulan başlangıç direkt ilişki matrisi Tablo 1'de verilmiştir.

Tablo 1. Başlangıç direkt ilişki matrisi (The initial directrelation matrix)

\begin{tabular}{|c|c|c|c|c|c|c|c|}
\hline $\begin{array}{c}\text { Ana } \\
\text { Faktörler }\end{array}$ & YO & AY & OE & OR & ET & MU & AG \\
\hline YO & 0 & 3 & 2 & 2 & 4 & 3 & 3 \\
\hline $\mathrm{AY}$ & 0 & 0 & 3 & 2 & 2 & 3 & 3 \\
\hline $\mathrm{OE}$ & 2 & 0 & 0 & 4 & 3 & 2 & 3 \\
\hline $\mathrm{OR}$ & 2 & 1 & 3 & 0 & 1 & 3 & 1 \\
\hline $\mathrm{ET}$ & 0 & 0 & 0 & 2 & 0 & 2 & 3 \\
\hline $\mathrm{MU}$ & 0 & 0 & 1 & 2 & 1 & 0 & 1 \\
\hline $\mathrm{AG}$ & 1 & 2 & 2 & 3 & 4 & 3 & 0 \\
\hline
\end{tabular}

Başlangıç direkt ilişki matrisinin DEMATEL tekniği ile çözümü neticesinde belirlenen ana faktörler arasındaki toplam ilişki matrisi ve D+R, D-R değerleri Tablo 2' de verilmiştir. Faktörler arasındaki etkileşimin örüntüsünün belirlenmesinde hesaplanan ortalama eşik değer -0.1623 'tür. Çalışmada eşik değerin daha düşük alınması durumunda ilişki örüntüsünün daha karmaşıklaştığı ve yüksek bir değerde ise olası ilişkilerin incelenememesi sorununa neden olduğu için, çalışmada DEMATEL analizi neticesinde oluşan örüntünün değerlendirilebilmesi ve açıklanabilmesi için eşik değer $-0,1623$ olarak alınmıştır.

Buna göre ana faktörler arasındaki örüntü şekil 3'de verilmiştir.

Tablo 2. Toplam ilişki matrisi ve $D+R$, $D-R$ değerleri (The total-relation matrix with $D+R, D-R$ values)

\begin{tabular}{|c|c|c|c|c|c|c|c|c|c|}
\hline Ana Faktörler & $\mathrm{YO}$ & $\mathrm{AY}$ & $\mathrm{OE}$ & $\mathrm{OR}$ & $\mathrm{ET}$ & $\mathrm{MU}$ & $\mathrm{AG}$ & $\mathrm{D}-\mathrm{R}$ & $\mathrm{D}+\mathrm{R}$ \\
\hline YO & $\mathrm{x}$ & 0,1679 & $\mathrm{x}$ & $\mathrm{x}$ & 0,0201 & $-0,1555$ & 0,0232 & $-0,1854$ & $-2,3286$ \\
\hline AY & $-0,1523$ & $\mathrm{x}$ & 0,0725 & $-0,1286$ & $\mathrm{x}$ & $-0,1592$ & $-0,0401$ & $-0,4976$ & $-1,993$ \\
\hline OE & 0,0466 & $-0,0678$ & $\mathrm{x}$ & $-0,1199$ & $-0,0262$ & $\mathrm{x}$ & $-0,0438$ & $-0,2168$ & $-2,4292$ \\
\hline OR & 0,1022 & 0,0347 & 0,0455 & $\mathrm{x}$ & $\mathrm{x}$ & $\mathrm{x}$ & $\mathrm{x}$ & 0,0894 & $-2,7014$ \\
\hline ET & $-0,1057$ & $-0,1183$ & $-0,147$ & 0,0591 & $\mathrm{x}$ & 0,1022 & 0,0699 & 0,3676 & $-1,9662$ \\
\hline MU & 0,0251 & $-0,1075$ & 0,0179 & 0,0538 & $-0,1147$ & $\mathrm{x}$ & $-0,1183$ & 0,518 & $-2,2742$ \\
\hline AG & $-0,1201$ & 0,0091 & $-0,0913$ & $-0,0815$ & $-0,0006$ & $-0,0848$ & $\mathrm{x}$ & $-0,0752$ & $-2,2124$ \\
\hline
\end{tabular}




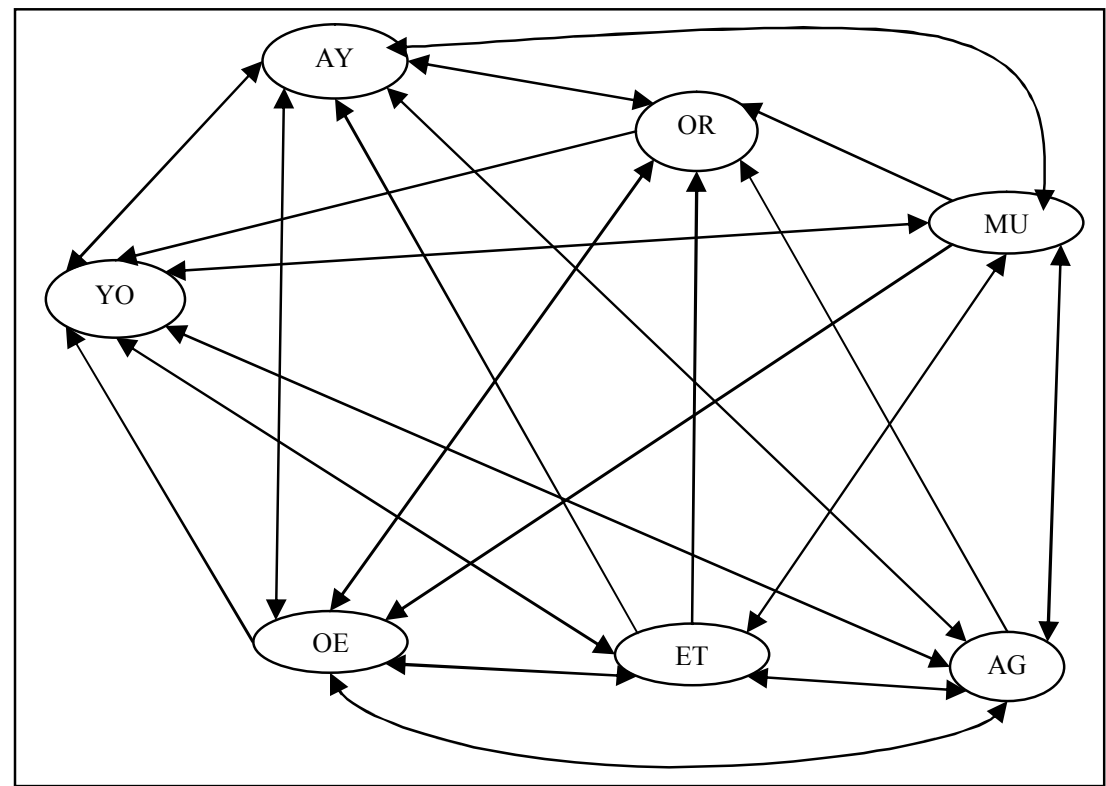

Şekil 3. Ana faktörler arasındaki ilişki (Relationship among the main factors)

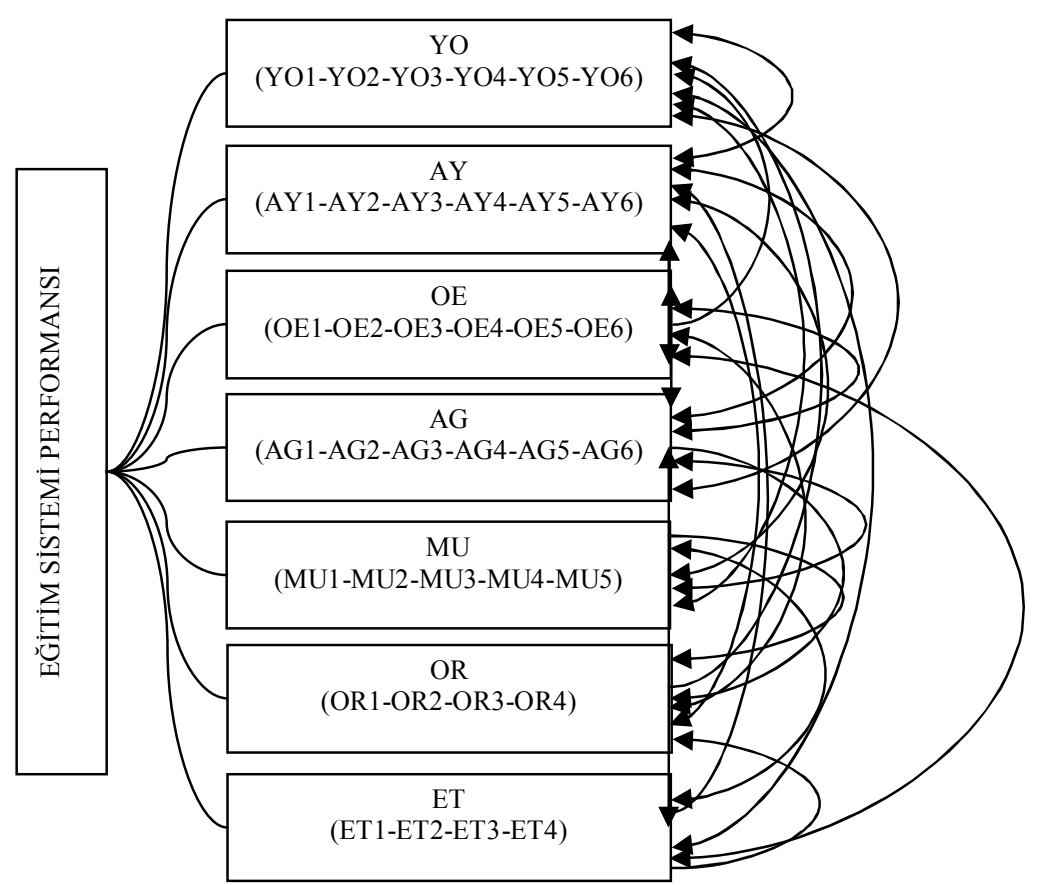

Şekil 4. DEMATEL sonucuna göre performans değerlendirme modeli (Performance assesment model according to the result of DEMATEL)

Adım 5: Eğitim sistemi performans değerlendirme modelinin oluşturulması. Çalışmanın dördüncü adımında DEMATEL tekniğiyle faktörler arasında belirlenen ilişki dikkate alınarak oluşturulan performans değerlendirme modeli şekil 4'de verilmiştir. Görüldüğü gibi başlangıç modelinde yargısal olarak faktörler arasında düşünülmemiş olan ilişkiler DEMATEL tekniğiyle saptanabilmiştir.
Adım 6: Eğitim sistemi faktörlerinin ilişkisizlik göreli ağırlıklarının belirlenmesi. Çalışmanın bu adımında eğitim sistemini oluşturan faktörlerin ilişkisizlik bağlamında ikili karşılaştırmaları yapılmış ve göreli ağırlıkları AHP tekniğiyle belirlenmiştir. Buna göre faktörler arasında ilişki dikkate alınmadan faktör ağırlıklarının belirlenmesi için oluşturulan ikili karşılaştırma matrisi ve hesaplanan ağırlıklar Tablo 3 'te verilmiştir. 
Adım 7: Eğitim sistemi faktörlerinin iç bağımlılık matrisinin oluşturulması. İç bağımlılık matrisinin belirlenmesi için şekil 2'deki ilişkiler dikkate alınarak sırasıyla Tablo 4'deki ikili karşılaştırma matrisleri düzenlenmiştir. İkili karşılaştırma matrislerindeki faktör ağırlıkları AHP tekniğiyle hesaplanmıştır.
Adım 8: Eğitim sistemi ana faktörleri iç bağımlılık ağırlıklarının hesaplanması. Çalışmanın altıncı adımında belirlenmiş olan ağırlıklar ile yedinci adımında belirlenen ağırlıkların çarpımıyla ana faktörlere ilişkin bağımlı ağırlıklar hesaplanmıştır (Tablo 5).

Tablo 3. Ana faktörlere ilişkin ikili karşılaştırma ve ağırlıklar (Pairwise comparision and weights related main factors)

\begin{tabular}{|l|l|l|l|l|l|l|l|l|}
\hline Faktörler & YO & AY & OE & OR & ET & MU & AG & Ağıllklar \\
\hline YO & 1 & 1 & $1 / 3$ & $1 / 3$ & 3 & 5 & 3 & 0,1389 \\
\hline AY & & 1 & $1 / 3$ & 1 & 3 & 7 & 3 & 0,1664 \\
\hline OE & & & 1 & 1 & 5 & 5 & 5 & 0,3041 \\
\hline OR & & & & 1 & 3 & 5 & 3 & 0,2228 \\
\hline ET & & & & & 1 & 3 & 1 & 0,0617 \\
\hline MU & & & & & & 1 & $1 / 7$ & 0,0290 \\
\hline AG & & & & & & & 1 & 0,0771 \\
\hline
\end{tabular}

Tablo 4. Ana faktörlerin iç bağımlılıklarına göre ikili karşılaştırma ve ağırlıklar (Pairwise comparison and weights according to inner dependence among the main factors)

\begin{tabular}{|c|c|c|c|c|c|c|c|c|c|}
\hline Faktörler & Alt Faktörler & $\mathrm{AY}$ & $\mathrm{OE}$ & OR & ET & MU & $\mathrm{AG}$ & Yerel Ağırlıklar & C.R. \\
\hline \multirow{6}{*}{ Yönetim } & AY & 1 & 3 & 3 & $1 / 3$ & 5 & 1 & 0,2044 & \multirow{6}{*}{0,05} \\
\hline & $\mathrm{OE}$ & & 1 & $1 / 3$ & $1 / 5$ & 3 & $1 / 5$ & 0,0643 & \\
\hline & OR & & & 1 & $1 / 3$ & 3 & $1 / 3$ & 0,1084 & \\
\hline & ET & & & & 1 & 5 & 1 & 0,3236 & \\
\hline & $\mathrm{MU}$ & & & & & 1 & $1 / 5$ & 0,0404 & \\
\hline & AG & & & & & & 1 & 0,2589 & \\
\hline \multirow{7}{*}{ Alt Yap1 } & & $\mathrm{YO}$ & $\mathrm{OE}$ & OR & ET & MU & $\mathrm{AG}$ & & \\
\hline & $\mathrm{YO}$ & 1 & 7 & 5 & 3 & 5 & 3 & 0,4161 & \multirow{6}{*}{0,06} \\
\hline & $\mathrm{OE}$ & & 1 & $1 / 3$ & $1 / 3$ & $1 / 3$ & $1 / 5$ & 0,0398 & \\
\hline & $\mathrm{OR}$ & & & 1 & $1 / 3$ & 3 & $1 / 3$ & 0,0968 & \\
\hline & ET & & & & 1 & 3 & 1 & 0,1763 & \\
\hline & MU & & & & & 1 & $1 / 5$ & 0,0626 & \\
\hline & $\mathrm{AG}$ & & & & & & 1 & 0,2085 & \\
\hline \multirow{6}{*}{ Öğretimin Etkililiği } & & $\mathrm{AY}$ & OR & ET & $\mathrm{MU}$ & $\mathrm{AG}$ & & & \\
\hline & AY & 1 & $1 / 5$ & 5 & 3 & 1 & & 0,1694 & \multirow{5}{*}{0,04} \\
\hline & OR & & 1 & 7 & 7 & 5 & & 0,5703 & \\
\hline & ET & & & 1 & 1 & $1 / 3$ & & 0,0536 & \\
\hline & MU & & & & 1 & $1 / 3$ & & 0,0580 & \\
\hline & $\mathrm{AG}$ & & & & & 1 & & 0,1487 & \\
\hline \multirow{6}{*}{ Öğrenciler } & & $\mathrm{AY}$ & $\mathrm{OE}$ & ET & $\mathrm{MU}$ & $\mathrm{AG}$ & & & \\
\hline & $\mathrm{AY}$ & 1 & $1 / 5$ & 3 & $1 / 3$ & 3 & & 0,1386 & \multirow{5}{*}{0,05} \\
\hline & $\mathrm{OE}$ & & 1 & 5 & 3 & 5 & & 0,4906 & \\
\hline & ET & & & 1 & $1 / 3$ & 1 & & 0,0686 & \\
\hline & MU & & & & 1 & 3 & & 0,2337 & \\
\hline & $\mathrm{AG}$ & & & & & 1 & & 0,0686 & \\
\hline \multirow{6}{*}{ Araştırma ve Geliştirme } & & $\mathrm{YO}$ & $\mathrm{AY}$ & $\mathrm{OE}$ & ET & MU & & & \\
\hline & $\mathrm{YO}$ & 1 & $1 / 3$ & 5 & 3 & 5 & & 0,2695 & \multirow{5}{*}{0,05} \\
\hline & $\mathrm{AY}$ & & 1 & 5 & 5 & 5 & & 0,4828 & \\
\hline & $\mathrm{OE}$ & & & 1 & $1 / 3$ & 1 & & 0,0597 & \\
\hline & ET & & & & 1 & 3 & & 0,1284 & \\
\hline & MU & & & & & 1 & & 0,0597 & \\
\hline \multirow{5}{*}{ Endüstri ve Toplum } & & YO & $\mathrm{OE}$ & MU & $\mathrm{AG}$ & & & & \\
\hline & YO & 1 & 3 & $1 / 3$ & $1 / 5$ & & & 0,1306 & \multirow{4}{*}{0,04} \\
\hline & $\mathrm{OE}$ & & 1 & $1 / 5$ & $1 / 5$ & & & 0,0656 & \\
\hline & MU & & & 1 & 1 & & & 0,3702 & \\
\hline & $\mathrm{AG}$ & & & & 1 & & & 0,4336 & \\
\hline \multirow{5}{*}{ Müfredat Dışı Etkinlikler } & & $\mathrm{YO}$ & $\mathrm{AY}$ & ET & $\mathrm{AG}$ & & & & \\
\hline & $\mathrm{YO}$ & 1 & 3 & 5 & 5 & & & 0,5596 & \multirow{4}{*}{0,02} \\
\hline & $\mathrm{AY}$ & & 1 & 3 & 3 & & & 0,2495 & \\
\hline & ET & & & 1 & 1 & & & 0,0955 & \\
\hline & AG & & & & 1 & & & 0,0955 & \\
\hline
\end{tabular}


Tablo 5. Ana faktörlere ilişkin bağımlı ağırlıklar (Dependent weights related main factors)

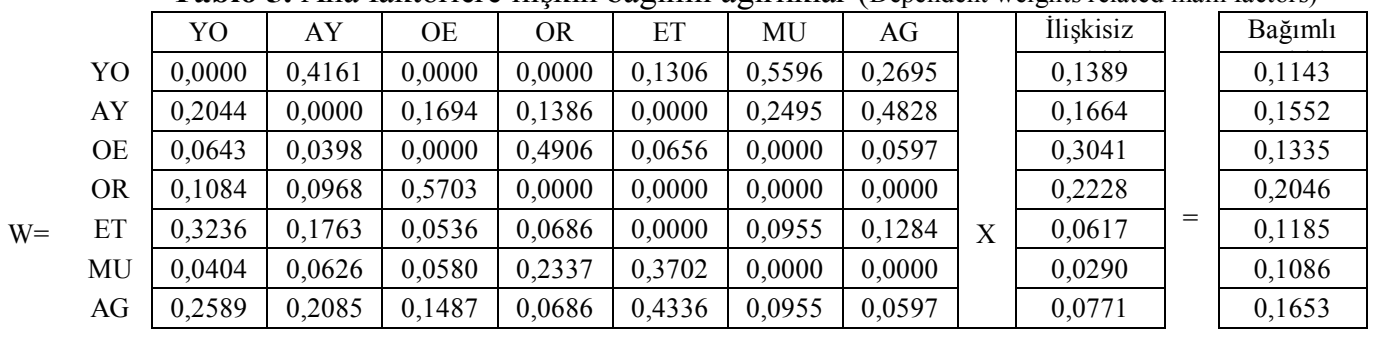

Tablo 6. Alt faktörlere ilişkin ikili karşılaştırma ve yerel ağırlıklar (Pairwise comparison and local weights related the sub factors)

\begin{tabular}{|c|c|c|c|c|c|c|c|c|c|}
\hline Ana Faktörler & Alt Faktörler & YO1 & $\mathrm{YO} 2$ & YO3 & YO4 & YO5 & YO6 & Yerel Ağırlıklar & $\mathrm{CR}$ \\
\hline \multirow{6}{*}{ Yönetim } & YO1 & 1 & 3 & $1 / 7$ & $1 / 5$ & $1 / 3$ & $1 / 5$ & 0,0516 & \multirow{6}{*}{0,05} \\
\hline & $\mathrm{YO} 2$ & & 1 & $1 / 7$ & $1 / 5$ & $1 / 3$ & $1 / 7$ & 0,0336 & \\
\hline & YO3 & & & 1 & 3 & 3 & 3 & 0,4020 & \\
\hline & YO4 & & & & 1 & 3 & 1 & 0,2015 & \\
\hline & YO5 & & & & & 1 & $1 / 3$ & 0,0993 & \\
\hline & YO6 & & & & & & 1 & 0,2121 & \\
\hline \multirow{7}{*}{ Altyap 1} & & AY1 & AY2 & AY3 & AY4 & AY5 & AY6 & & \\
\hline & AY1 & 1 & $1 / 3$ & 7 & 9 & 3 & 3 & 0,2773 & \multirow{6}{*}{0,06} \\
\hline & AY2 & & 1 & 7 & 7 & 3 & 3 & 0,3955 & \\
\hline & AY3 & & & 1 & 3 & $1 / 3$ & $1 / 3$ & 0,0501 & \\
\hline & AY4 & & & & 1 & $1 / 5$ & $1 / 3$ & 0,0307 & \\
\hline & AY5 & & & & & 1 & 3 & 0,1508 & \\
\hline & AY6 & & & & & & 1 & 0,0957 & \\
\hline \multirow{7}{*}{$\begin{array}{l}\text { Öğretimin } \\
\text { Etkilililiği }\end{array}$} & & OE1 & OE2 & OE3 & OE4 & OE5 & OE6 & & \\
\hline & OE1 & 1 & $1 / 9$ & $1 / 5$ & 3 & $1 / 3$ & 1 & 0,0563 & \multirow{6}{*}{0,07} \\
\hline & OE2 & & 1 & 7 & 9 & 5 & 7 & 0,5592 & \\
\hline & OE3 & & & 1 & 5 & 3 & 3 & 0,1856 & \\
\hline & OE4 & & & & 1 & $1 / 5$ & $1 / 3$ & 0,0295 & \\
\hline & OE5 & & & & & 1 & 1 & 0,1014 & \\
\hline & OE6 & & & & & & 1 & 0,0707 & \\
\hline \multirow{7}{*}{$\begin{array}{l}\text { Araştırma ve } \\
\text { Geliş̧irme }\end{array}$} & & AG1 & AG2 & AG3 & AG4 & AG5 & AG6 & & \\
\hline & AG1 & 1 & 3 & 3 & $1 / 5$ & $1 / 5$ & 5 & 0,1212 & \multirow{6}{*}{0,06} \\
\hline & AG2 & & 1 & 1 & $1 / 7$ & $1 / 7$ & 5 & 0,0616 & \\
\hline & AG3 & & & 1 & $1 / 5$ & $1 / 5$ & 5 & 0,0681 & \\
\hline & AG4 & & & & 1 & 1 & 9 & 0,3624 & \\
\hline & AG5 & & & & & 1 & 9 & 0,3624 & \\
\hline & AG6 & & & & & & 1 & 0,0242 & \\
\hline \multirow{6}{*}{$\begin{array}{l}\text { Müfredat Diş1 } \\
\text { Etkinlikler }\end{array}$} & & MU1 & MU2 & MU3 & MU4 & MU5 & & & \\
\hline & MU1 & 1 & $1 / 3$ & $1 / 5$ & $1 / 3$ & 3 & & 0,0936 & \multirow{5}{*}{0,05} \\
\hline & MU2 & & 1 & 1 & 3 & 5 & & 0,3292 & \\
\hline & MU3 & & & 1 & 3 & 5 & & 0,3651 & \\
\hline & MU4 & & & & 1 & 3 & & 0,1592 & \\
\hline & MU5 & & & & & 1 & & 0,0529 & \\
\hline \multirow{5}{*}{ Öğrenciler } & & OR1 & OR2 & OR3 & OR4 & & & & \\
\hline & OR1 & 1 & 3 & 7 & 9 & & & 0,5772 & \multirow{4}{*}{0,07} \\
\hline & OR2 & & 1 & 5 & 9 & & & 0,3014 & \\
\hline & OR3 & & & 1 & 3 & & & 0,0821 & \\
\hline & OR4 & & & & 1 & & & 0,0394 & \\
\hline \multirow{5}{*}{$\begin{array}{l}\text { Endüstri ve } \\
\text { Toplumla } \\
\text { Etkileşim }\end{array}$} & & ET1 & ET2 & ET3 & ET4 & & & & \\
\hline & ET1 & 1 & $1 / 3$ & $1 / 3$ & 3 & & & 0,1393 & \multirow{4}{*}{0,05} \\
\hline & ET2 & & 1 & $1 / 3$ & 5 & & & 0,2788 & \\
\hline & ET3 & & & 1 & 7 & & & 0,5254 & \\
\hline & ET4 & & & & 1 & & & 0,0565 & \\
\hline
\end{tabular}


Adım 9: Eğitim sistemi alt faktörlerinin göreli ağırlıklarının hesaplanması. Çalışmanın bu adımında her bir ana faktörü oluşturan alt faktörlere ilişkin ikili karşılaştırmalar yapılmış ve ağırlıklar AHP tekniğiyle belirlenmiştir (Tablo 6).

Adım 10: Eğitim sistemini oluşturan faktörlerin genel ağırlıkların belirlenmesi. Eğitim sisteminin performansının belirlenmesine temel oluşturacak ağırlıklar sekizinci adımda belirlenmiş olan faktör bağımlı ağırlıklar ile dokuzuncu adımda hesaplanmış olan faktör yerel ağırlıkların çarpımıyla belirlenmiştir (Tablo 8).

Adım 11: Performans düzeyinin belirlenmesi. $\mathrm{Bu}$ adımda uzman ekibin görüşlerine göre oluşturulmuş olan ve çok ölçütlü bir çalışmada [10] kullanılan ölçek bu çalışmanın bağlamına uyarlanarak, eğitim sisteminin içerdiği faktörlerin performans düzey durumu değerlendirilmiştir (Tablo 7).
Tablo 7. Alt faktör performans değerlendirme ölçeği (Scale for asessesment performance of sub-factor)

\begin{tabular}{|l|l|}
\hline Performans düzeyi & Değer \\
\hline Çok iyi $(\mathrm{VG})$ & 1,00 \\
\hline İyi $(\mathrm{G})$ & 0,75 \\
\hline Orta $(\mathrm{M})$ & 0,50 \\
\hline Olumsuz $(\mathrm{N})$ & 0,25 \\
\hline Çok olumsuz $(\mathrm{VN})$ & 0,00 \\
\hline
\end{tabular}

Karar vericinin değerlendirilmesinde kullanılan ölçek çok olumsuz (0.00) düzey ile çok iyi düzey (1.00) arasında değer alan beş düzeyden oluşmaktadır.

Tablo 7'de verilen ölçek kullanılarak araştırma kapsamındaki bölümün her bir alt faktör temelindeki performans değerlendirilmesi yapılmıştır. $\mathrm{Bu}$ değerlendirmeler Tablo 8'deki altıncs sütunda verilmiştir. Tablo 8'in yedinci sütununda ise sözel değerlendirmelerin karşılı̆̆ almaktadır. Sekizinci sütunda ise beşinci sütunda

Tablo 8. Genel ağırlıklar ve performans düzeyi (Global weights and performance level)

\begin{tabular}{|c|c|c|c|c|c|c|c|}
\hline $\begin{array}{c}\text { Ana } \\
\text { Faktörler }\end{array}$ & $\begin{array}{c}\text { Bağımlı } \\
\text { Ăğırlıklar }\end{array}$ & $\begin{array}{c}\text { Alt } \\
\text { Faktörler }\end{array}$ & $\begin{array}{c}\text { Yerel } \\
\text { Ağırlıklar }\end{array}$ & $\begin{array}{c}\text { Genel } \\
\text { Ağırlıklar } \\
\text { (ga) } \\
\end{array}$ & $\begin{array}{l}\text { Mevcut } \\
\text { Durum }\end{array}$ & $\begin{array}{l}\text { Değer } \\
\text { (d) }\end{array}$ & $\begin{array}{c}\text { Performans } \\
\text { Düzeyi } \\
\text { ga } \times \mathbf{d} \\
\end{array}$ \\
\hline \multirow{6}{*}{ YO } & \multirow{6}{*}{0,1143} & YO1 & 0,0516 & 0,0059 & $\mathrm{G}$ & 0,75 & 0,0044 \\
\hline & & YO2 & 0,0336 & 0,0038 & $\mathrm{M}$ & 0,50 & 0,0019 \\
\hline & & YO3 & 0,4020 & 0,0459 & $\mathrm{M}$ & 0,50 & 0,0230 \\
\hline & & YO4 & 0,2015 & 0,0230 & $\mathrm{VG}$ & 1,00 & 0,0230 \\
\hline & & YO5 & 0,0993 & 0,0113 & VG & 1,00 & 0,0113 \\
\hline & & YO6 & 0,2121 & 0,0242 & VG & 1,00 & 0,0242 \\
\hline \multirow{6}{*}{ AY } & \multirow{6}{*}{0,1552} & AY1 & 0,2773 & 0,0430 & $\mathrm{G}$ & 0,75 & 0,0323 \\
\hline & & AY2 & 0,3955 & 0,0614 & $\mathrm{G}$ & 0,75 & 0,0461 \\
\hline & & AY3 & 0,0501 & 0,0078 & $\mathrm{M}$ & 0,50 & 0,0039 \\
\hline & & AY4 & 0,0307 & 0,0048 & $\mathrm{M}$ & 0,50 & 0,0024 \\
\hline & & AY5 & 0,1508 & 0,0234 & $\mathrm{G}$ & 0,75 & 0,0176 \\
\hline & & AY6 & 0,0957 & 0,0149 & $\mathrm{G}$ & 0,75 & 0,0112 \\
\hline \multirow{6}{*}{$\mathrm{OE}$} & \multirow{6}{*}{0,1335} & OE1 & 0,0563 & 0,0075 & $\mathrm{M}$ & 0,50 & 0,0038 \\
\hline & & OE2 & 0,5592 & 0,0747 & $\mathrm{M}$ & 0,50 & 0,0374 \\
\hline & & OE3 & 0,1856 & 0,0248 & $\mathrm{M}$ & 0,50 & 0,0124 \\
\hline & & OE4 & 0,0295 & 0,0039 & $\mathrm{~N}$ & 0,25 & 0,0010 \\
\hline & & OE5 & 0,1014 & 0,0135 & $\mathrm{M}$ & 0,50 & 0,0068 \\
\hline & & OE6 & 0,0707 & 0,0094 & $\mathrm{G}$ & 0,75 & 0,0071 \\
\hline \multirow{4}{*}{ OR } & \multirow{4}{*}{0,2046} & OR1 & 0,5772 & 0,1181 & $\mathrm{~N}$ & 0,25 & 0,0295 \\
\hline & & OR2 & 0,3014 & 0,0617 & $\mathrm{~N}$ & 0,25 & 0,0154 \\
\hline & & OR3 & 0,0821 & 0,0168 & $\mathrm{~N}$ & 0,25 & 0,0042 \\
\hline & & OR4 & 0,0394 & 0,0081 & $\mathrm{M}$ & 0,50 & 0,0041 \\
\hline \multirow{4}{*}{ ET } & \multirow{4}{*}{0,1185} & ET1 & 0,1393 & 0,0165 & $\mathrm{~N}$ & 0,25 & 0,0041 \\
\hline & & ET2 & 0,2788 & 0,0330 & $\mathrm{~N}$ & 0,25 & 0,0083 \\
\hline & & ET3 & 0,5254 & 0,0623 & $\mathrm{~N}$ & 0,25 & 0,0156 \\
\hline & & ET4 & 0,0565 & 0,0067 & $\mathrm{~N}$ & 0,25 & 0,0017 \\
\hline \multirow{5}{*}{ MU } & \multirow{5}{*}{0,1086} & MU1 & 0,0936 & 0,0102 & $\mathrm{~N}$ & 0,25 & 0,0026 \\
\hline & & MU2 & 0,3292 & 0,0358 & $\mathrm{VN}$ & 0,00 & 0,0000 \\
\hline & & MU3 & 0,3651 & 0,0396 & $\mathrm{G}$ & 0,75 & 0,0297 \\
\hline & & MU4 & 0,1592 & 0,0173 & $\mathrm{VN}$ & 0,00 & 0,0000 \\
\hline & & MU5 & 0,0529 & 0,0057 & $\mathrm{~N}$ & 0,25 & 0,0014 \\
\hline \multirow{6}{*}{$\mathrm{AG}$} & \multirow{6}{*}{0,1653} & AG1 & 0,1212 & 0,0200 & $\mathrm{~N}$ & 0,25 & 0,0050 \\
\hline & & AG2 & 0,0616 & 0,0102 & $\mathrm{M}$ & 0,50 & 0,0051 \\
\hline & & AG3 & 0,0681 & 0,0113 & $\mathrm{VN}$ & 0,00 & 0,0000 \\
\hline & & AG4 & 0,3624 & 0,0599 & $\mathrm{~N}$ & 0,25 & 0,0150 \\
\hline & & AG5 & 0,3624 & 0,0599 & $\mathrm{~N}$ & 0,25 & 0,0150 \\
\hline & & AG6 & 0,0242 & 0,0040 & $\mathrm{VN}$ & 0,00 & 0,0000 \\
\hline \multicolumn{4}{|c|}{ Toplam } & 1,0000 & & & 0,4259 \\
\hline
\end{tabular}


verilen her bir faktörün genel ağırlığı ile yedinci sütundaki faktör durum sayısal değerlerinin çarpımı bulunmaktadır. Bu değerler her bir faktörün mevcut performans düzeyini göstermektedir. Örneğin YO1 faktörün eğitim sistemi içerisindeki genel ağırlığı 0,0059'dur. $\mathrm{Bu}$ genel ağırlık değeri eğitim sistemi içerisinde $\mathrm{YO} 1$ 'in alabileceği en yüksek değerdir. Bir diğer deyişle eğitim sistemin bir bütün olarak işleyişinde YO1'den beklenen performans düzeyini ifade etmektedir. Ancak performans değerlendirmesi sonucunda YO1'in gözlemlenen düzeyi 0,0044 olmuştur. YO1 faktörünün genel ağırlık düzeyi ile performans düzeyi arasındaki fark ilgili faktörün sapma değerini belirtmektedir. Öte yandan YO4, YO5, YO6 faktörlerinde ise sapma düzeyinin bulunmadığ1 görülmektedir. MU2, MU4, AG3, AG6 faktörlerinde ise sapma düzeyinin \% 100 olduğu saptanmıştır. Tablo 8'in son satırında görüldüğü gibi araştırma kapsamındaki lisans programının bu çalışmanın temel aldığg 1 faktörlerin değerlendirilmesine göre performans düzeyinin \% 42,59 olduğu görülmüştür. Eğitim sisteminin performans düzeyinden sapması ise $\% \quad 57$ düzeyindedir.

\section{TARTIŞMA VE SONUÇLAR (DISCUSSION AND CONCLUSIONS)}

Bu çalışmada, eğitim faaliyetinin doğasının çok faktörlü bir yapıya sahip olduğu düşüncesinden hareketle, bir eğitim sisteminin performansını değerlendirmeye yönelik bir algoritma önerilmiştir. Performans değerlendirme algoritması eğitim olgusunun temel karakteristiklerini dikkate alan bir yaklaşımla yapılandırılmıştır. Çalışmada önerilen algoritmanın uygulaması bir üniversitenin lisans düzeyinde eğitim veren bir bölümüne yönelik yapılmıştır. Çalışmanın sonuçları, eğitim faaliyetinin diğer sistemleri konu edinen çalışmalarda $[14,20]$ olduğu gibi ÇÖKV teknikleriyle modellenebildiğini ve çözümlenebildiğini göstermiştir. Önerilen algoritma ile bir eğitim sisteminin bütüncül düzeyde performans değerlendirmesinin yapılabileceği tespit edilmiştir. Sonuçlar incelendiğinde performans değerlendirme algoritmasında başlangıçta eğitim sistemini oluşturan faktörler arasında yargısal olarak belirlenmiş ilişkiler ile DEMATEL tekniğiyle belirlenen ilişkilerden farklı bulunmuştur. DEMATEL sonuçlarının daha ayrıntılı ve kapsamlı ilişki örüntüsüne sahip olduğunu ve dolayısıyla faktörler arasında öngörülen ilişkinin geçerliliği açısından önemli bulgular verdiğini göstermektedir. DEMATEL tekniğinin bu üstünlüğüne karşılık, faktörler arasındaki ilişki örüntüsünün kullanılan eşik değere göre farklılık gösterebilmesi dikkate alınması gereken önemli bir konudur. Bütüncül yaklaşımı temel alan bu çalışmanın sonuçlarına göre bir eğitim sisteminin performansının ne düzeyde gerçekleştiği belirlenebilmiştir. Eğitim sisteminin performansının belirlenmesi eğitim yöneticileri, karar vericiler ve planlamacılar açısından bilinmesi gereken önemli bir bilgidir. Çalışmada önerilen algoritmayla elde edilen bir diğer sonuç ise her bir eğitim faktörünün performans düzeyinin belirlenmesidir. Bu sonuç yine eğitim yöneticilerinin karar verme sürecinde gereksinim duyduğu bilgiler açısından önemlidir. Çalışmanın bir diğer sonucu faktörlere göre performans sapma düzeyinin ve eğitim sisteminin genel performans sapma düzeyinin hesaplanabilmiş olmasıdır. Çalışmanın sonucunda ulaşılan bu bilgiler bir sistemin etkililiği açısından gereksinim duyulan verilerdir.

Bir sistemin performansının biliniyor olması karar verme ve dolayısıyla eğitim yöneticileri açısından önemli olmakla birlikte gelecek zaman diliminde ve koşullarında eğitim sisteminin performansının öngörülmesinin stratejik kararlar ve planlama açısından önemli olacağı söylenebilir. Bu düşünceden hareketle bir sistemin performansinı belirleyen modele gelecekteki durum ve koşulları dikkate alan çalışmalar yapılabilir. $\mathrm{Bu}$ çalışmanın devamında yapılabilecek diğer bir çalışma da BSC bağlamında eğitim sistemi boyutları ile modellenen bir performans değerlendirmesinin yapılabilmesidir. Bundan sonra yapılabilecek çalışmalarda ilişki örüntüsünde belirleyici olan eşik değeri araştırma konusu edinen araştırmalar yapılabilir. Özellikle araştırma konusunun kavramsal boyutunu destekleyecek bir eşik değeri belirlemeye yönelik bir çalışma yapılabilir.

\section{KAYNAKLAR (REFERENCES)}

1. Baykul, Y., "Eğitim Sisteminde Değerlendirme", Hacettepe Üniversitesi Eğitim Fakültesi Dergisi, No 7, 85-94, 1992.

2. Gürsel, M., Türk Eğitim Sistemi ve Okul Yönetimi, Eğitim Yayınevi, Konya, 2012.

3. Poveda-Bautista, R., Baptista, D.C. ve GarciaMelon, M., "Setting competitiveness indicators using BSC and ANP", International Journal of Production Research, Cilt 50, No 17, 47384752, 2012.

4. Taylor, F.W., Bilimsel Yönetimin İlkeleri, (Çev. H. B. Akın), Adres Yayınları, Ankara, 2005.

5. Kaptanoğlu, D. ve Özok, A.F., "Akademik Performans değerlendirmesi için bir bulanık model", ITÜ Dergisi /d mühendislik, Cilt 5, No 1, 193-204, 2006.

6. Wu, H-Y., Tzeng, G-H. ve Chen, Y-H., “A fuzzy MCDM approach for evaluating banking performance based on Balanced Scorecard", Expert Systems with Applications, Cilt 36, No 6, 10135-10147, 2009.

7. Kaplan, R. S. ve Norton, D., "The balanced scorecard measures that drive Performance", Harvard Business Review, Cilt 70, No 1, 71-79, 1992.

8. Kaplan, R.S. ve Norton, D.P., Balanced Scorecard Şirket Stratejisini Eyleme 
Dönüştürmek, (Çev. S. Egeli), Sistem Yayıncılık, İstanbul, 1996.

9. Kaplan, R.S.ve Norton, D.P., "Using the balanced scorecard as a strategic management systems", Harvard Business Review, Cilt 74, No 1, 75-85, 1996.

10. Yüksel, İ. ve Dağdeviren, M., "Using the fuzzy analytic network process (ANP) for Balanced Scorecard (BSC): A case study for a manufacturing firm", Expert Systems With Applications, Cilt 37, No 2, 1270-1278, 2010.

11. Abran, A. ve Buglione, L., "A multidimensional performance model for consolidating balanced scorecards", Advances in Engineering Software, Cilt 34, No 6, 339-349, 2003.

12. Lee, A.H.I., Chen, W.C. ve Chang, C.J., "A fuzzy AHP and BSC approach for evaluating performance of IT department in the manufacturing industry in Taiwan", Expert Systems with Applications, Cilt 34, No 1, 96107, 2008.

13. Leung, L.C., Lam, K.C. ve Cao, D., "Implementing the balanced scorecard using the Analytic Hierarchy process \& the analytic network Process", Journal of the Operational Research Society, Cilt 57, No 6, 682-691, 2006.

14. Tseng, M-L., "Implementation and performance evaluation using the fuzzy network balanced Scorecard", Computers \& Education, Cilt 55, No 1, 188-201, 2010.

15. Sohn, M.H., You, T., Lee, S-L. ve Lee, H., Corporate strategies, environmental forces, and performance measures: a weighting decision support system using the $k$-nearest neighbor tehchnique, Expert Systems with Applications, Cilt 25, No 3, 279-292, 2003.

16. Kang, H-Y., Hung, M-C., Pearn, W.L., Lee, A.H.I. ve Kang, M-S., "An Integrated MultiCriteria Decision Making Model for Evaluating Wind Farm Performance", Energies, Cilt 4, No 11, 2002-2026, 2011.

17. Chen, J-K. ve Chen, I-S., "Using a novel conjunctive MCDM approach based on DEMATEL, fuzzy ANP, and TOPSIS as an innovation support system for Taiwanese higher education", Expert Systems with Applications, Cilt 37, No 3, 1981-1990, 2010.

18. Chen, J-K. ve Chen, I-S., "A Pro-performance appraisal system for the university", Expert Systems with Applications, Cilt 37, No 3, 21082116, 2010.

19. Hu, H-Y., Lee, Y-C., Yen, T-M. ve Tsai, C-H., "Using BPNN and DEMATEL to modify importance-performance analysis model- A study of the computer industry", Expert Systems with Applications, Cilt 36, No 6, 9969-9979, 2009.

20. Chen, F-H., Hsu, T-S. ve Tzeng, G-H., "A balanced scorecard approach to establish a performance evaluation and relationship model for hot spring hotels based on a hybrid MCDM model combining DEMATEL and ANP", International Journal of Hospitality Management, Cilt 30, No 4, 908-932, 2011.

21. Ho, L-H., Feng, S-Y., Lee, Y-C. ve Yen, T-M., "Using modified IPA to evaluate supplier's performance: Multiple regression analysis and DEMATEL approach", Expert Systems with Applications, cilt 39, No 8, 7102-7109, 2012.

22. Ateş, N.Y., Çevik, S., Kahraman, C., Gülbay, M. ve Erdoğan, S.A. "Multi Attribute Performance Evaluation Using a Hierarchical Fuzzy TOPSIS Method", Studies Fuzziness and soft computing, Cilt 21, 537-572, 2006.

23. Kabak, M., Köse, E., Kırılmaz, O. ve Burmaoğlu, S., "A fuzzy multi-criteria decision making approach to assess building energy performance", Energy and Buildings, Cilt 72, 382-389, 2014.

24. $\mathrm{Wu}, \mathrm{H}-\mathrm{Y}$., "Constructing a strategy map for banking institutions with key performance indicators of the balanced Scorecard", Evaluation and Program Planning, Cilt 35, No 3, 303-320, 2012.

25. $\mathrm{Wu}, \mathrm{H}-\mathrm{Y}$., Lin, $\mathrm{Y}-\mathrm{K}$. ve Chang, C-H., "Performance evaluation of extension education centers in universities based on the balanced Scorecard", Evaluation and Program Planning, Cilt 34, No 1, 37-50, 2011.

26. Yüksel, İ. ve Dağdeviren, M., "Sosyo-Teknik Sistemlerde Hatalı Davranış Riskini Belirlemeye Yönelik Bir Erken Uyarı Modeli", Journal of The Faculty of Engineering and Architecture of Gazi University, Cilt 21, No 4, 791-799, 2006.

27. Yüksel, İ., "Developing a Multi-Criteria Decision Making Model for PESTEL Analysis", International Journal of Business and Management, Cilt 7, No 24, 52-66, 2012.

28. Aksakal, E. ve Dağdeviren, M., "ANP ve DEMATEL Yöntemleri İle Personel Seçimi Problemine Bütünleşik Bir Yaklaşım”, Journal of The Faculty of Engineering and Architecture of Gazi University, Cilt 25, No 4, 905-913, 2010.

29. Shieh, J-I., Wu, H-H. ve Huang, K-K., "A DEMATEL method in identifying key success factors of hospital service quality", KnowledgeBased Systems, Cilt 23, No 3, 277-282, 2010.

30. Tseng, M-L., "Using hybrid MCDM to evaluate the service quality expectation in linguistic preference", Applied Soft Computing, Cilt 11, No 8, 4551-4562, 2011.

31. Li, Y., Hu, Y., Zhang, X. ve Deng, Y., "An evidential DEMATEL method to identiy critical success factors in emergency management", Applied Soft Computing, Cilt 22, No 8, 504510, 2014.

32. Lin, Y-T., Yang, Y-H., Kang, J-S. ve Yu, H-C., "Using DEMATEL method to explore the core competences and causal effect of the IC design service company: An empirical case study", 
Expert Systems with Applications, Cilt 38, No 5, 6262-6268, 2011.

33. Saaty, T.L., The Analytic Hierarchy Process, McGraw-Hill, New York, 1980.

34. Saaty, TL., "Axiomatic Foundation of the Analytic Hierarchy Process". Management Science, Cilt 32, No 7, 841-855, 1986.

35. Saaty, T.L., "Some Mathematical Concepts of the Analytic Hierarchy Process", Behaviormetrika, Cilt 18, No 29, 1-9, 1991.

36. Saaty, T.L., Decision Making with Dependence and Feedback: The Analytic Network Process, RWS Publications, Pittsburgh, 1996.

37. Dağdeviren, M., "A hybrid multi-criteria decision-making model for personnel selection in manufacturing systems", Journal of Intelligent Manufacturing, Cilt 21, No 4, 451-460, 2010.
38. Sahu, A., Shrivastava, R.L. ve Shrivastava, R.R., "Key factors affecting the effectiveness of technical education-an indian perspective", Proceedings of the World Congress on Engineering, London, U.K.,1232-1236, 2-4 July ,2008.

39. Gupta, R., Garg, T.K., Gupta, S. ve Goel, A., "Decision Anaylsis Approcach for Quality in Technical Education", Global Journal of Human Social Science, Cilt 10, No 1, 14-18, 2010.

40. Tsinidou, M., Gerogiannis, V. ve Fitsilis, P., "Evaluation of the factors that determine quality in higher education: an empirical study", Quality Assurance in Education, Cilt 18, No 3, 227-244, 2010. 
